\title{
Genetic and neurocognitive contributions to the development of psychopathy
}

\author{
ESSI VIDING AND EAMON J. MCCRORY \\ University College London
}

\begin{abstract}
An overview is provided of recent twin, molecular genetic, and magnetic resonance imaging studies that are helping to inform a model of developmental vulnerability to adult psychopathy. Although the current evidence base suggests that children with high levels of callous-unemotional traits are genetically and neurocognitively vulnerable to developing psychopathic and antisocial behaviors, existing research also clearly indicates that environmental influences play an important role. One potential implication is that interventions for children with antisocial behavior and callous-unemotional traits may need to be tailored to take into account their distinct pattern of neurocognitive vulnerability, as revealed by developmental neuroimaging studies. Specifically, interventions that pursue punishment-oriented or explicit empathy induction strategies may be less effective with this group of antisocial children. By contrast, preliminary evidence suggests that enhancing positive parenting and parental involvement, as well as applying consistent rewards may represent more promising intervention approaches.
\end{abstract}

Callous-unemotional (CU) traits include lack of guilt and empathy, as well as shallow affect. Adults with a combination of CU traits and antisocial behavior $(\mathrm{AB})$ are labeled psychopaths within the criminal justice system (Hare \& Neumann, 2006). Although no one would suggest that children are psychopaths, CU traits can be used to distinguish a subgroup of children who are capable of premeditated $\mathrm{AB}$ and violence (AB/CU+; Frick \& Viding, 2009) and who are at an elevated risk for developing psychopathy when they reach adulthood (Lynam, Derefinko, Caspi, Loeber, \& Stouthamer-Loeber, 2007). CU traits are currently being considered as a subtyping criterion for the fifth edition of the Diagnostic and Statistical Manual of Mental Disorders of the American Psychiatric Association (Frick \& Moffitt, 2010; Scheepers, Buitelaar, \& Matthys, 2011). A number of clinical and community studies suggest that children who have early-onset $\mathrm{AB}$ are more likely to have elevated levels of $\mathrm{CU}$ traits than those in the adolescent-onset group, but both groups include $\mathrm{AB} / \mathrm{CU}+$ individuals (Dandreaux \& Frick, 2009; Silverthorn, Frick, \& Reynolds, 2001; Vizard, Hickey, \& McCrory, 2007). In line with this, the proposed inclusion of "with CU traits" as a conduct disorder diagnostic specifier in the next edition of the DSM applies to any child with a conduct disorder diagnosis, regardless of the age of onset (Frick \& Moffitt, 2010).

This work was supported by British Academy Award 2353229 and Economic and Social Research Council Award RES-062-23-2202 (to E.V. and E.J.M.).

Address correspondence and reprint requests to: Essi Viding, Division of Psychology and Language Sciences, University College London, Gower Street, London WC1 6BT, United Kingdom; E-mail: e.viding@ucl.ac.uk.
Longitudinal data show that children with $\mathrm{AB} / \mathrm{CU}+$ present with a more severe behavioral profile and more longterm problems than children who have $\mathrm{AB}$ but lower levels of CU (AB/CU-; Fontaine, McCrory, Boivin, Moffitt, \& Viding, 2011; Frick \& Viding, 2009). Even in the absence of AB, $\mathrm{CU}$ traits are associated with poorer outcomes, including risk for developing delinquent behaviors and other types of psychosocial maladjustment (e.g., Barker, Oliver, Viding, Salekin, \& Maughan, 2011; Frick, Cornell, Barry, Bodin, \& Dane, 2003; Kumsta, Sonuga-Barke, \& Rutter, in press; Rowe, Costello, Angold, Copeland, \& Maughan, 2010). Longitudinal data also show that $\mathrm{CU}$ traits add to the prediction of serious and persistent criminal behavior in boys (Pardini \& Fite, 2010). In short, the core affective characteristics of psychopathy (CU traits) can be delineated in children and may be a risk index for later psychopathy, as well as other forms of poor outcome.

Cognitive experimental data suggest that children with $\mathrm{AB} / \mathrm{CU}+$ are poor at modulating their behavior in response to punishment in conditioning paradigms (for a review, see Frick \& Viding, 2009). In addition they have difficulties in processing other people's fearful and sad facial expressions, vocal tones, and body postures (e.g., Blair \& Viding, 2008; Marsh \& Blair, 2008; Muñoz, 2009), which may at least partially derive from failure to orient to the affectively salient aspects of stimuli (Dadds et al., 2006; Dadds, Jambrak, Pasalich, Hawes, \& Brennan, 2011; Dadds \& Rhodes, 2008; Sylvers, Brennan, \& Lilienfeld, 2011). Children with AB/ $\mathrm{CU}+$ also appear to have an impoverished personal experience of fear and guilt, which suggests that their difficulty in processing others' distress may partly stem from an inability 
to feel normative levels of distress themselves (de Wied, van Boxtel, Mathys, \& Meeus, 2011; Jones, Happé, Gilbert, Burnett, \& Viding, 2010; Marsh et al., 2010). Theoretical accounts of $\mathrm{AB} / \mathrm{CU}+$ propose that normal socialization is disrupted in these children because they do not form adequate associations between their transgressions and punishment outcome and because they do not find other people's distress aversive and consequently have difficulties in developing empathy (Blair, 2010; Blair \& Viding, 2008). This affective profile is in contrast to that commonly found for children with $\mathrm{AB} / \mathrm{CU}-$, who are often hypervigilant to threat emotions, are capable of showing empathy, and can appear emotionally overreactive (Frick \& Viding, 2009; Jones, Happé, Gilbert, Burnett, \& Viding, 2010).

The aim of this paper is to provide an overview of recent genetically informative and magnetic resonance imaging (MRI) studies of $\mathrm{AB} / \mathrm{CU}+$ and discuss how these data have furthered our understanding of developmental vulnerability to psychopathy. We use examples of our own and others' research to illustrate how a developmental psychopathology approach, employing multiple levels of analyses and considering concepts such as equi- and multifinality, is essential for garnering a better understanding of how psychopathy develops and how it can be prevented. We also discuss the potential treatment implications of the existing genetic and neurocognitive research. Although there is now a substantial body of behavioral and cognitive experimental studies attesting to the distinct nature of $\mathrm{AB} / \mathrm{CU}+$, evidence from genetic and neuroimaging research remains preliminary. We will finish by outlining the necessary directions for future research.

\section{Etiology of CU Traits}

A number of twin studies have examined the etiology of CU traits in children and youth. These studies come from the United States, Sweden, and the United Kingdom. The samples used in these studies vary in size from moderate (398 twin pairs) to large (3,687 twin pairs), represent different age groups (7-24 years old), and have used a range of instruments that have relied on both self- and other (parent or teacher) ratings (see Table 1 for details of the samples, ages, and measures). We will concentrate specifically on genetically informative data on $\mathrm{CU}$ traits or $\mathrm{AB} / \mathrm{CU}+$, because $\mathrm{CU}$ traits represent the core affective features of psychopathy (Frick \& Viding, 2009).

Twin studies estimate heritability by establishing the degree to which identical twins (who effectively share 100\% of their polymorphic genes) compared to nonidentical twins (who on average share 50\% of their polymorphic genes) are similar to each other. If identical twin similarity exceeds nonidentical twin similarity, then heritable influences on a trait are inferred. The existing studies have reported remarkably consistent results of moderate to strong heritability for $\mathrm{CU}$ traits in children and youth. These studies, conducted across different age groups and using different measures of $\mathrm{CU}$ traits, estimate that $40 \%$ to $78 \%$ of the variation in CU traits across the population is attributable to genetic influences (Bezdjian, Raine, Baker, \& Lynam, 2011; Blonigen, Hicks, Krueger, Patrick, \& Iacono, 2005, 2006; Fontaine, Rijsdijk, McCrory, \& Viding, 2010; Larsson, Andershed, \& Lichtenstein, 2006; Taylor, Loney, Bobadilla, Iacono, \& McGue, 2003; Viding, Frick, \& Plomin, 2007). Our own data from the Twins Early Development Study (TEDS) has also indicated that at age 7 the group difference between those scoring at the high end for CU traits (top 10\%) and other children is also largely driven by genetic influences $\left(h_{\mathrm{g}}^{2}=0.67\right.$; Viding, Blair, Moffitt, \& Plomin, 2005). These group heritability estimates appear very similar regardless of whether the $\mathrm{CU}$ occurs with $\left(h_{\mathrm{g}}^{2}=0.80\right)$ or without $\left(h_{\mathrm{g}}^{2}=0.68\right)$ elevated levels of AB (Larsson, Viding, \& Plomin, 2008).

Twin studies are also important for documenting the extent to which environmental factors influence individual differences or group differences in CU traits. The shared environment in twin studies refers to environmental factors that make the members of the twin pair more similar than would be expected by genetic relatedness alone (this can be crudely inferred if nonidentical twin similarity exceeds $50 \%$ of identical twin similarity). The nonshared environment in twin studies refers to environmental factors that make members of the twin pair dissimilar to each other (this can be crudely inferred if identical twin similarity is less than 100\%). Shared environmental influences were detected in only few cases for CU (Fontaine et al., 2010; Viding, Frick, \& Plomin, 2007), but our longitudinal data (described more fully below) indicate that such influences may be particularly important for a handful of girls who have stable and high levels of CU. All studies, including our own, have demonstrated that nonshared environmental influences are particularly important for the development of CU. This does not mean that family or neighborhood environments are not relevant for development of CU. Rather it suggests that environmental risk factors, including those experienced within the family context, are likely to promote differences between members of the same family (nonshared environment in the twin models). The magnitude of the heritability and environmental estimates for CU traits from child and adolescent samples are in line with previous adult twin data on psychopathic personality traits (Blonigen, Carlson, Krueger, \& Patrick, 2003) as well as other personality dimensions (Bouchard \& Loehlin, 2001).

\section{Are There Sex Differences in the Etiology of CU Traits?}

Four studies to date (Bezdjian et al., 2011; Fontaine et al., 2010; Larsson et al., 2006; Viding et al., 2007) have incorporated dizygotic opposite-sex twin pairs in their analyses and formally explored the potential role of qualitative sex differences (i.e., different genes and environments influencing phenotypic variation for males and females). None of these studies have reported qualitative sex differences for CU traits. A 
Table 1. Summary table of twin, molecular genetic, and neuroimaging studies of child/adolescent $C U$ or $A B / C U+$

\begin{tabular}{|c|c|c|c|c|}
\hline Sample & Authors & $N$, Sex & Age (years) & CU Measure \\
\hline & & \multicolumn{3}{|c|}{ Twin Studies } \\
\hline $\begin{array}{l}\text { Southern California Twin } \\
\text { Project }\end{array}$ & $\begin{array}{l}\text { Bezdjian et al. } \\
\quad(2011)\end{array}$ & $\begin{array}{l}605 \text { pairs, } 49 \% \\
\text { boys }\end{array}$ & 9.6 & $\begin{array}{l}\text { Child Psychopathy Scale } \\
\text { (caregiver report; self-report) }\end{array}$ \\
\hline \multirow[t]{2}{*}{$\begin{array}{l}\text { Minnesota Twin and } \\
\text { Family Study }\end{array}$} & $\begin{array}{l}\text { Taylor et al. } \\
\text { (2003) }\end{array}$ & $\begin{array}{l}398 \text { pairs, all } \\
\text { boys }\end{array}$ & $16-18$ & $\begin{array}{l}\text { Scale drawn using items from the } \\
\text { Minnesota Temperament } \\
\text { Inventory (self-report) }\end{array}$ \\
\hline & $\begin{array}{l}\text { Blonigen et al. } \\
\quad(2005)\end{array}$ & $\begin{array}{l}626 \text { pairs, } 46 \% \\
\text { boys }\end{array}$ & 17 & $\begin{array}{l}\text { Scale drawn using items from the } \\
\text { Multidimensional Personality } \\
\text { Questionnaire (self-report) }\end{array}$ \\
\hline
\end{tabular}

Blonigen et al. $\quad 626$ pairs, $46 \% \quad 17,24$ (2006) boys

TEDS

$\begin{array}{ccc}\begin{array}{c}\text { Viding et al. } \\ (2005)\end{array} & \begin{array}{c}3,500+\text { pairs, } \\ 47 \% \text { boys }\end{array} & 7 \\ & \\ & \\ \text { Viding et al. } & \begin{array}{c}3,500+\text { pairs, } \\ \text { (2007) }\end{array} & 7 \\ & 47 \% \text { boys } & \\ & \\ \text { Larsson et al. } & \begin{array}{l}3,500+\text { pairs, } \\ \text { (2008) }\end{array} & 77 \% \text { boys }\end{array}$

Multidimensional Personality

Questionnaire (self-report)

Scale drawn using items from the
Multidimensional Personality Questionnaire (self-report)

Items from the Antisocial Process Screening Device CUScale and the Strengths and Difficulties Questionnaire (teacher report)

Items from the Antisocial Process Screening Device CUScale and the Strengths and Difficulties Questionnaire (teacher report)

Antisocial Process Screening Device CU-Scale and the Strengths and Difficulties Questionnaire (teacher report)
Main Findings ${ }^{a}$

Genetic influences accounted for $57 \%$ of the variance in $\mathrm{CU}$ traits.

Nonshared environmental influences explained the remaining variance.

Strong genetic correlation ${ }^{b}$ between CU traits and aggression, in particular between self-reported $\mathrm{CU}$ traits and proactive aggression $\left(r_{\mathrm{g}}=.76\right)$

Genetic influences accounted for $40 \%$ of the variance in $\mathrm{CU}$ traits.

Nonshared environmental influences explained the remaining variance.

Strong genetic correlation between CU traits and antisocial behavior $\left(r_{\mathrm{g}}=.78\right)$

Genetic influences accounted for $45 \%$ of the variance in $\mathrm{CU}$ traits.

Nonshared environmental influences explained the remaining variance.

Only modest genetic overlap between CU traits and antisocial behavior $\left(r_{\mathrm{g}}=.16\right)$

Genetic influences accounted for $42 \%$ of the variance in the $\mathrm{CU}$ scale.

Nonshared environmental influences explained the remaining variance.

Stability of CU traits was to a large extent (58\%) accounted for by genetic factors.

The group difference in antisocial behavior between those scoring at the top $10 \%$ of the TEDS sample and the rest of the TEDS children was under strong genetic influence in children with high levels of CU $\left(h_{\mathrm{g}}^{2}=0.81\right),{ }^{c}$ but not in children with low levels of $\mathrm{CU}\left(h_{\mathrm{g}}^{2}=0.30\right)$.

Individual differences in CU traits were heritable.

No qualitative sex differences.

Quantitative sex differences: higher heritability of CU for males ( $67 \% \mathrm{M}$ vs. $48 \% \mathrm{~F})$.

Substantial genetic overlap between $\mathrm{CU}$ and antisocial behavior $\left(r_{\mathrm{g}}=.57\right.$ boys, $r_{\mathrm{g}}=.65$ girls $)$ The group difference in CU between those scoring at the top $10 \%$ of the TEDS sample and the rest of the TEDS children was heritable at age 7, and the estimates were similar regardless of whether the CU occurred with $\left(h_{\mathrm{g}}^{2}=0.80\right)$ or without $\left(h_{\mathrm{g}}^{2}=\right.$ 0.68 ) elevated levels of antisocial behavior. 
Table 1 (cont.)

\begin{tabular}{|c|c|c|c|c|c|}
\hline Sample & Authors & $N$, Sex & Age (years) & CU Measure & Main Findings ${ }^{a}$ \\
\hline \multicolumn{6}{|c|}{ Twin Studies } \\
\hline \multirow{8}{*}{$\begin{array}{l}\text { The Swedish Twin Study } \\
\text { of Child and Adolescent } \\
\text { Development }\end{array}$} & $\begin{array}{l}\text { Viding et al. } \\
\text { (2008) }\end{array}$ & $\begin{array}{l}1,865 \text { pairs, } 47 \% \\
\text { boys }\end{array}$ & 9 & $\begin{array}{l}\text { Antisocial Process Screening } \\
\text { Device CU-Scale and the } \\
\text { Strengths and Difficulties } \\
\text { Questionnaire (teacher report) }\end{array}$ & $\begin{array}{l}\text { This study replicated the finding of different } \\
\text { heritability estimates for the antisocial behavior of } \\
\text { high CU and low CU groups. The heritability } \\
\text { differences remained after controlling for } \\
\text { hyperactivity scores. }\end{array}$ \\
\hline & $\begin{array}{l}\text { Viding et al. } \\
\text { (2009) }\end{array}$ & $\begin{array}{l}2,254 \text { pairs, } 46 \% \\
\text { boys }\end{array}$ & 7,12 & $\begin{array}{l}\text { Antisocial Process Screening } \\
\text { Device CU-Scale and the } \\
\text { Strengths and Difficulties } \\
\text { Questionnaire (teacher report) }\end{array}$ & $\begin{array}{l}\text { Negative parental discipline was a nonshared } \\
\text { environmental risk factor for antisocial behavior, } \\
\text { but not for CU. }\end{array}$ \\
\hline & $\begin{array}{l}\text { Fontaine et al. } \\
\quad(2010)\end{array}$ & $\begin{array}{l}9,462 \text { twins, } \\
47 \% \text { boys }\end{array}$ & $7,9,12$ & $\begin{array}{l}\text { Antisocial Process Screening } \\
\text { Device CU-Scale and the } \\
\text { Strengths and Difficulties } \\
\text { Questionnaire (teacher report) }\end{array}$ & $\begin{array}{l}\text { Trajectory modeling from age } 7 \text { to } 12 \\
\text { Quantitative sex differences: stable high CU highly } \\
\text { heritable for boys }\left(h^{2}=0.78\right) \text {, but almost entirely } \\
\text { driven by shared environmental influences for } \\
\text { girls }\left(c^{2}=75 \%\right)\end{array}$ \\
\hline & $\begin{array}{l}\text { Larsson et al. } \\
\qquad(2006)\end{array}$ & $\begin{array}{l}1,090 \text { pairs, } 48 \% \\
\text { boys }\end{array}$ & 16 & $\begin{array}{l}\text { Youth Psychopathic Traits } \\
\text { Inventory (self-report) }\end{array}$ & $\begin{array}{l}\text { Genetic influences accounted for } 43 \% \text { of the } \\
\text { variance in CU traits. } \\
\text { Nonshared environmental influences explained the } \\
\text { remaining variance. }\end{array}$ \\
\hline & $\begin{array}{l}\text { Larsson et al. } \\
\text { (2007) }\end{array}$ & $\begin{array}{r}2,387 \text { twins } \\
48 \% \text { boys }\end{array}$ & $13-14,16-17$ & $\begin{array}{l}\text { Youth Psychopathic Traits } \\
\text { Inventory (self-report) }\end{array}$ & $\begin{array}{l}\text { A common genetic factor contributed substantially } \\
\text { to all psychopathic personality dimensions } \\
\text { (including CU). } \\
\text { This common factor had genetic overlap with } \\
\text { antisocial behavior. }\end{array}$ \\
\hline & $\begin{array}{l}\text { Forsman et al. } \\
\text { (2007) }\end{array}$ & $\begin{array}{l}\text { Over } 2,000 \\
\text { twins, } 48 \% \\
\text { boys }\end{array}$ & $\begin{array}{l}8-9,13-14 \\
16-17\end{array}$ & $\begin{array}{l}\text { Youth Psychopathic Traits } \\
\text { Inventory (self-report) }\end{array}$ & $\begin{array}{l}\text { Genetic factors accounted for the longitudinal } \\
\text { association between externalizing behavior and } \\
\text { psychopathic personality traits in boys. }\end{array}$ \\
\hline & $\begin{array}{l}\text { Forsman et al. } \\
\text { (2008) }\end{array}$ & $\begin{array}{l}\text { Over } 2,000 \\
\text { twins, } 48 \% \\
\text { boys }\end{array}$ & $16-19$ & $\begin{array}{l}\text { Youth Psychopathic Traits } \\
\text { Inventory (self-report) }\end{array}$ & $\begin{array}{l}\text { Test-retest correlation of the higher-order } \\
\text { psychopathic personality factor was high }(r= \\
.60) \text {, and as much as } 90 \% \text { of the test-retest } \\
\text { correlation was explained by genetic factors. } \\
\text { Evidence for specific genetic stability of CU traits }\end{array}$ \\
\hline & $\begin{array}{l}\text { Forsman et al. } \\
\quad(2009)\end{array}$ & $\begin{array}{r}2,255 \text { twins, } \\
48 \% \text { boys }\end{array}$ & $\begin{array}{c}8-9,16-17 \\
19-20\end{array}$ & $\begin{array}{l}\text { Youth Psychopathic Traits } \\
\text { Inventory (self-report) }\end{array}$ & $\begin{array}{l}\text { Psychopathic personality in adolescence predicted } \\
\text { antisocial behavior in early adulthood. }\end{array}$ \\
\hline \multicolumn{6}{|c|}{ Molecular Genetic Studies } \\
\hline $\begin{array}{l}\text { Adolescents from a genetic } \\
\text { study of ADHD }\end{array}$ & $\begin{array}{l}\text { Fowler et al. } \\
\quad(2009)\end{array}$ & $147,93 \%$ males & 17 & $\begin{array}{l}\text { Psychopathy Checklist-Youth } \\
\text { Version Emotional } \\
\text { Dysfunction Scale }\end{array}$ & $\begin{array}{l}C O M T \mathrm{val} / \mathrm{val}, 5-H T T L P R s, \text { and } M A O A-\mathrm{L} \\
\text { genotypes associated with increased CU traits in } \\
\text { youth with ADHD }\end{array}$ \\
\hline $\begin{array}{l}\text { Study 1: Rural sample of } \\
\text { adolescents recruited } \\
\text { from treatment/legal } \\
\text { agencies and } \\
\text { community }\end{array}$ & $\begin{array}{l}\text { Sadeh et al. } \\
\quad(2010)\end{array}$ & $\begin{array}{r}\text { Study 1: } 118 \\
42 \% \text { males }\end{array}$ & Study 1: 14 & $\begin{array}{l}\text { Study 1: } \\
\text { Antisocial Process Screening } \\
\text { Device (self-report) }\end{array}$ & $\begin{array}{l}\text { 5-HTTLPRl associated with increased CU in } \\
\text { children from lower socioeconomic status } \\
\text { background in both study samples }\end{array}$ \\
\hline
\end{tabular}


Study 2: Community sample from urban setting

TEDS
Study 2: 178,

$55 \%$ males

Viding et al. (2010)

\section{$\mathrm{AB} / \mathrm{CU}+: 593$. \\ TD: 593;}

$69 \%$ males
Study 2: 11

Unemotional Traits (self-

report)

Antisocial Process Screening

Device CU-Scale and the

Strengths and Difficulties

Questionnaire Conduct

Problem Scale (teacher report)

Genome-wide association study using pooled DNA

Nothing reached genome-wide significance.

Tentative hits near neurodevelopmental genes such as $\mathrm{ROBO} 2$

Neuroimaging Studies: Functional Magnetic Resonance Imaging

Community sample through ads and

referrals for mental

health professionals

Community sample through ads and referrals for mental health professionals

Community sample through ads and referrals for menta health professionals

Community sample from schools, pupil referral units, and the

Cambridge Youth Offending Service

Community sample from schools and through ads

\section{Marsh et al.} (2008)

Finger et al.

(2008)

Jones et al. (2009)

Finger et al.
(2011)
Passamonti
et al. (2010)

Sebastian et al.
(in press)
(in press)
CU: $12 ; 58 \%$ male

ADHD: $12 ; 68 \%$ male

TD: $12 ; 50 \%$

male

Psychopathic traits with $\mathrm{CD}$ or ODD: 14 ; $64 \%$ male

ADHD: $14 ; 71 \%$ male

TD: $14 ; 64 \%$ male

CU: 17; all male

TD: 13; all male

$\begin{array}{ll}\text { CU: } 14.5 & \text { Antisocial Process Screening } \\ \text { ADHD: } 13.8 & \text { Device; Psychopathy } \\ \text { TD: } 14.2 & \text { Checklist-Youth Version; } \\ & \text { Youth Psychopathic Traits } \\ & \text { Inventory }\end{array}$

Psychopathic

Psychopathic traits with $\mathrm{CD}$ or ODD: 15 ; $60 \%$

TD: $15 ; 60 \%$

EO-CD: 27; all male

AO-CD: 25; all male

TD: $23 ; 100 \%$ all male
CP: 31; all male

TD: 16; all male traits with CD or ODD: 13.8 ADHD: 13.4

TD: 13.6

Antisocial Process Screening Device; Psychopathy Checklist-Youth Version

Antisocial Process Screening Device; Strengths and Difficulties Questionnaire (combined parent and teacher ratings)

Psychopathic Antisocial Process Screening

Device; The Psychopathy $\begin{array}{ll}\text { traits with } & \text { Device; The Psychopathy } \\ \text { CD or ODD: } & \text { Checklist-Youth Version }\end{array}$ 14.1

TD: 13.2

EO-CD: 17.7

AO-CD: 17.1

TD: 17.8

Youth Psychopathic Traits Inventory (self-rated)

CP: 14.3

TD: 13.5
Inventory of Callous-

Unemotional Traits and the Child and Adolescent

Symptom Inventory conduct disorder subscale (combined parent and teacher ratings)
Compared to TD and ADHD, those with CU traits showed reduced amygdala activation when viewing fearful expressions.

Greater correlations between amygdala and ventromedial prefrontal cortex in TD and ADHD groups compared to $\mathrm{CU}$ traits group

Abnormal ventromedial prefrontal cortex response in psychopathic traits group during punished reversal errors, compared to ADHD and TD groups

Reduced amygdala activation to fearful faces in $\mathrm{CP} /$ CU traits group compared to TD group

CU traits group showed reduced orbitofrontal responsivity to early stimulus-reinforcement exposure and to rewards compared to the TD group.

Reduced caudate responsivity to early stimulusreinforcement exposure in same sample

Although group differences in amygdala activity to sad and neutral faces emerged between both CD groups as compared with the TD group, $\mathrm{CU}$ traits did not predict the degree of amygdala activation to these facial expressions.

Unique variance on $\mathrm{CU}$ traits negatively associated with amygdala activity to affective theory of mind scenarios in children with $\mathrm{CP}$

Unique variance on $\mathrm{CD}$ symptoms positively associated with amygdala activity to affective theory of mind scenarios in children with $\mathrm{CP}$ 
Table 1 (cont.)

\begin{tabular}{|c|c|c|c|c|c|}
\hline Sample & Authors & $N$, Sex & Age (years) & CU Measure & Main Findings ${ }^{a}$ \\
\hline \multicolumn{6}{|c|}{ Twin Studies } \\
\hline
\end{tabular}

Structural Magnetic Resonance Imaging

\begin{tabular}{|c|c|c|c|c|c|}
\hline $\begin{array}{l}\text { Boys drawn from the } \\
\text { TEDS }\end{array}$ & $\begin{array}{l}\text { De Brito et al. } \\
\text { (2009) }\end{array}$ & $\begin{array}{l}\mathrm{AB} / \mathrm{CU}+: 23 \\
\text { all male } \\
\mathrm{TD}: 25 ; \text { all male }\end{array}$ & $\begin{array}{l}\mathrm{AB} / \mathrm{CU}+: 8.1 \\
\mathrm{TD}: 11.8\end{array}$ & $\begin{array}{l}\text { Antisocial Process Screening } \\
\text { Device and Strengths and } \\
\text { Difficulties Questionnaire } \\
\text { (combined parent and teacher } \\
\text { ratings) }\end{array}$ & $\begin{array}{l}\text { Increased grey matter concentration in the } \mathrm{AB} / \mathrm{CU}+ \\
\text { compared to TD group, in several brain areas } \\
\text { including the medial orbitofrontal, posterior and } \\
\text { anterior cingulate cortices, and temporal lobes } \\
\text { bilaterally }\end{array}$ \\
\hline $\begin{array}{l}\text { Boys drawn from the } \\
\text { TEDS }\end{array}$ & $\begin{array}{l}\text { De Brito et al. } \\
\text { (2011) }\end{array}$ & $\begin{array}{l}\mathrm{AB} / \mathrm{CU}+: 23 \\
\text { all male } \\
\mathrm{TD}: 25 ; \text { all male }\end{array}$ & $\begin{array}{l}\mathrm{AB} / \mathrm{CU}+: 8.1 \\
\mathrm{TD}: 11.8\end{array}$ & $\begin{array}{l}\text { Antisocial Process Screening } \\
\text { Device and Strengths and } \\
\text { Difficulties Questionnaire } \\
\text { (combined parent and teacher } \\
\text { ratings) }\end{array}$ & $\begin{array}{l}\text { For the } \mathrm{AB} / \mathrm{CU}+\text { group compared to the TD group, } \\
\text { decreased white matter concentration was found } \\
\text { in several brain areas including the anterior } \\
\text { cingulate and superior temporal cortex. }\end{array}$ \\
\hline $\begin{array}{l}\text { Community sample from } \\
\text { schools, pupil referral } \\
\text { units, and the } \\
\text { Cambridge Youth } \\
\text { Offending Service }\end{array}$ & $\begin{array}{l}\text { Fairchild et al. } \\
\text { (2011) }\end{array}$ & $\begin{array}{l}\text { EO-CD: } 36 \text {; all } \\
\text { male } \\
\text { AO-CD: } 27 \text {; all } \\
\text { male } \\
\text { TD: } 27 \text {; all male }\end{array}$ & $\begin{array}{l}\text { EO-CD: } 17.7 \\
\text { AO-CD: } 17.9 \\
\text { TD: } 18.5\end{array}$ & $\begin{array}{l}\text { Inventory of Callous- } \\
\text { Unemotional Traits and Youth } \\
\text { Psychopathic Traits Inventory }\end{array}$ & $\begin{array}{l}\text { CU traits predicted increased caudate nucleus and } \\
\text { ventral striatal grey matter volumes in children } \\
\text { with } C D \text {. }\end{array}$ \\
\hline
\end{tabular}

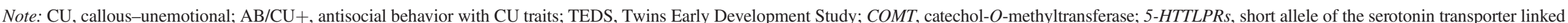

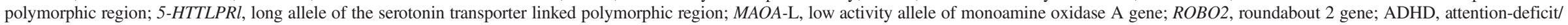
hyperactivity disorder; TD, typically developing; ODD, oppositional defiant disorder; EO-CD, early onset conduct disorder; AO-CD, late onset conduct disorder; CP, conduct problems.

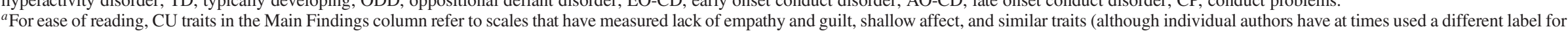
their scale, e.g., "detachment"). The CU Measure column lists the specific CU measure. Interested readers should consult the individual papers for further details of the measures.

${ }^{b} r_{\mathrm{g}}$ is the genetic correlation (the degree of genetic overlap).

${ }^{c} h_{\mathrm{g}}^{2}$ is the group heritability (the degree of group differences due to genetic influences). 
number of studies have also assessed the possibility of quantitative sex differences (i.e., the same genetic and environmental influences affecting males and females to a different degree). Two studies found little evidence of quantitative sex differences for CU traits (Blonigen et al., 2006; Larsson et al., 2006), but there is also some support for a higher heritability of CU for males (Bezdijan et al., 2011; Fontaine et al., 2010; Viding et al., 2007). For instance, using data from 9,462 youths from the TEDS, Fontaine and colleagues found that strong heritability $\left(h^{2}=0.78\right)$ was observed for boys on a stable high CU trajectory (between 7 and 12 years old). Stable and high levels of CU in girls, however, appeared to be almost entirely driven by shared environmental influences $\left(c^{2}=0.75\right)$. Replication of this finding is needed given the small number of children who followed the stable and high CU trajectory and the even smaller proportion of this already small group who were females $(<1 \%$ of the total sample).

\section{Stability of CU Traits: Genetic and Environmental Contributions}

A few twin studies to date have explored the genetic and environmental contributions to the stability of CU traits in childhood and adolescence. Blonigen et al. (2006) focused on two time points 7 years apart, when the twins were 17 and 24 years old. Their results indicate that the heritability of $\mathrm{CU}$ traits remained consistent across time and $58 \%$ of the stability of CU traits was due to genetic influences. This finding indicates that the stability in CU traits is substantially influenced by genetic factors. Using the TEDS sample, Fontaine and colleagues (2010) reported that a stable high trajectory of CU in childhood (between 7 and 12 years) was strongly heritable in boys $\left(h^{2}=0.78\right)$ but not in girls $\left(h^{2}=0.00\right)$. This finding suggests that at least in childhood/early adolescence, genetic influences may drive the stability of high levels of CU traits for boys in particular. Forsman, Lichtenstein, Andershed, and Larsson (2008) measured CU traits (as well as impulsivity and grandiosity) and examined genetic and environmental contributions to the stability of these traits between ages 16 and 19. The authors focused on a hierarchical model of psychopathic personality in which a higher-order general factor substantially explained the variation in the three psychopathic personality dimensions in mid- and late adolescence. The results showed that the observed test-retest correlation of the higher-order psychopathic personality factor was high ( $r=$ .60). In addition, as much as $90 \%$ of the test-retest correlation was explained by genetic factors. However, they also found evidence for specific genetic stability in CU. Thirteen percent of the unique genetic effects in the $\mathrm{CU}$ dimension at age 19 were shared with the corresponding effects at age 16. Thus, their model provides evidence for etiologic generality (together with other aspects of psychopathic personality) and etiologic specificity for the stability of $\mathrm{CU}$ traits between mid- and late adolescence. Note that for a subset of children, CU traits are malleable in childhood, increasing or decreasing with age, rather than remaining persistently high or low (see Fontaine et al., 2010). This may reflect environmental factors interacting with genetic risk to either promote or moderate the development of $\mathrm{CU}$ traits, leading to increasing or decreasing CU trajectories, respectively (Fontaine et al., 2010). The challenge for researchers and clinicians is to identify the key environmental factors that are most influential in this regard and to develop interventions that can promote the reduction of $\mathrm{CU}$ traits, thereby reducing the risk of later maladaptive outcomes.

\section{Etiological Overlap Between CU Traits and AB}

Twin models have also been important in exploring the etiologic overlap between $\mathrm{CU}$ traits and AB. Multivariate genetic models can be used to estimate the extent of genetic/environmental correlation, which refers to the degree of overlap between genetic/environmental influences on different traits or behaviors. Three multivariate twin studies to date have demonstrated a moderate to high genetic correlation between $\mathrm{CU}$ traits and $\mathrm{AB} /$ aggression when covariation is measured in the whole population (range of $r_{\mathrm{g}}=.41-.74$; Bezdijan et al., 2011; Taylor et al., 2003; Viding et al., 2007), whereas one study to date has reported a modest genetic correlation between $\mathrm{CU}$ traits and $\mathrm{AB}\left(r_{\mathrm{g}}=.16\right.$; Blonigen et al., 2005). The genetic overlap may be slightly stronger at the extreme high end of both $\mathrm{CU}$ and $\mathrm{AB}$ distributions (Viding et al., 2007). Larsson et al. (2007) explored the genetic commonality between three psychopathic personality dimensions (grandiose-manipulative, $\mathrm{CU}$, and impulsive-irresponsible) and $\mathrm{AB}$ measured at age 13-14 and age 16-17 years. A common genetic factor loaded substantially on both psychopathic personality traits and $\mathrm{AB}$. This was not the case for environmental factors. Forsman, Larsson, Andershed, and Lichtenstein (2007) found that externalizing behavior in childhood (age 8-9) was associated with higher levels of psychopathic personality traits in adolescence (age 13-14) among boys but not in girls. Genetic factors were responsible for this association. Another study by Forsman, Lichtenstein, Andershed, and Larsson (2010) showed that a psychopathic personality in adolescence (16-17) predicted AB in early adulthood (19-20), over and above both concurrent and preexisting levels of $\mathrm{AB}$. The association between adolescent psychopathic personality and adult $\mathrm{AB}$ was mainly explained by genetic effects, a result that can be interpreted as a genetically influenced personality-driven process, where individuals are predisposed to higher risk of involvement in $\mathrm{AB}$ because of their psychopathic personality. Finally, a recent study by Bezdjian et al. (2011) demonstrated that CU traits shared genetic influences with both reactive and proactive aggression. The genetic correlation was particularly strong between selfrated CU traits and proactive aggression $\left(r_{\mathrm{g}}=.76\right)$.

With regard to environmental influences, modest to moderate nonshared environmental correlations have been demonstrated between $\mathrm{CU}$ traits and AB/aggression (e.g., Bezdijan et al., 2011; Viding et al., 2007). This means that, 
although some child-specific environmental factors promote the development of both $\mathrm{CU}$ and AB/aggression, the childspecific environmental influences for the two constructs also have substantial independence. We recently conducted a longitudinal monozygotic twin differences study to examine negative parental discipline (e.g., shouting and harsh discipline) as a nonshared environmental factor for $\mathrm{CU}$ and AB (Viding, Fontaine, Oliver, \& Plomin, 2009). Although negative parental discipline at age 7 had a phenotypic association with both $\mathrm{CU}$ traits and $\mathrm{AB}$ at age 12, negative parental discipline emerged as a nonshared environmental factor for $\mathrm{AB}$ alone. In other words those members of the monozygotic twin pair who received more negative parental discipline at age 7 were also more likely to manifest $\mathrm{ABs}$ at age 12, even after controlling for baseline differences in the level of AB. This was not true for CU traits; and we speculated that the phenotypic association between negative parental discipline and CU traits may reflect the genetic endowment within those families with $\mathrm{CU}+$ children, rather than an environmentally driven parenting process that increases risk for CU traits.

\section{Etiology of AB With and Without CU Traits}

Finally, twin studies have also been helpful in exploring the utility of $\mathrm{CU}$ traits as a subtyping factor for individuals with AB. Viding et al. (2005) used information from the TEDS sample to investigate whether the etiology of teacher rated $\mathrm{AB}$ differs as a function of teacher rated $\mathrm{CU}$ at age 7. The authors separated children with elevated levels of $\mathrm{AB}$ (in the top $10 \%$ for the TEDS sample) into two groups based on their CU score (in the top $10 \%$ or not). AB in children with CU was under strong genetic influence $\left(h_{\mathrm{g}}^{2}=0.81\right)$ and no influence of shared environment. In contrast, $\mathrm{AB}$ in children without elevated levels of CU showed moderate genetic influence $\left(h_{\mathrm{g}}^{2}=0.30\right)$ and substantial environmental influence $\left(c_{\mathrm{g}}^{2}=0.34, e_{\mathrm{g}}^{2}=0.26\right)$. Viding, Jones, Frick, Moffitt, and Plomin (2008) replicated the finding of different heritability estimates for the $\mathrm{AB} / \mathrm{CU}+$ and $\mathrm{AB} / \mathrm{CU}-$ groups using the 9-year teacher data from the TEDS. In addition, they demonstrated that the strong heritability of $\mathrm{AB}$ in the $\mathrm{AB} / \mathrm{CU}+$ group was not driven by co-occurring hyperactivity.

\section{Molecular Genetic Studies}

Despite the substantial literature demonstrating the heritable component of CU traits, we know of only three published molecular genetic studies of child/adolescent CU traits (see Table 1 for details of these studies). The first of these was carried out on a relatively small sample of adolescents with attentiondeficit/hyperactivity disorder (ADHD) and reported associations between "emotional dysfunction" scores of psychopathy $(\mathrm{CU})$ and each of the following allelic variants: the valine allele of the cathechol- $O$-methyltransferase gene, the low activity allele of the monoamine oxidase A gene (MAOA-L), and the short allele of the serotonin transporter linked poly- morphic region gene (5-HTTLPRs; Fowler et al., 2009). The latter two of these associations were unexpected given that imaging genetic data suggesting that $M A O A-\mathrm{L}$ and 5 HTTLPRs are associated with heightened amygdala activity to emotional stimuli (e.g., Meyer-Lindenberg et al., 2006; Munafo, Brown, \& Hariri, 2008), in contrast to the reduced amygdala activity to emotional stimuli typically seen in adults with psychopathy and children with $\mathrm{AB} / \mathrm{CU}+$ (reduced; e.g., Birbaumer et al., 2005; Jones et al., 2009; Kiehl et al., 2001; Marsh et al., 2008). It is possible that the findings of Fowler and colleagues are specific to the selected group of adolescents that they studied, all of whom had high levels of ADHD symptoms but relatively low levels of CU traits. A more recent study reported that the long allele of the 5HTTLPR (5-HTTLPRl), which is the allele conferring low amygdala reactivity, was associated with CU traits in adolescents from low socioeconomic status backgrounds (Sadeh et al., 2010). This is an extremely interesting finding, because it tentatively suggests that vulnerability to low emotional reactivity may only manifest as high CU traits under disadvantageous socioeconomic conditions.

Finally, new technologies, such as DNA pooling, are enabling genome-wide association studies that search for novel single nucleotide polymorphisms (SNPs), which may be associated with $\mathrm{AB} / \mathrm{CU}+$. DNA pooling refers to a genetic screening method that combines DNA from many individuals in a single molecular genetic analysis to generate a representation of allele frequencies. A DNA pool can thus be generated for all cases and all controls and allele frequencies can be compared between these pools. We recently conducted such a study and, although no SNPs reached genomewide significance, there were some potential candidates near neurodevelopmental genes (Viding et al., 2010). If these findings are replicated, these novel SNPs could be assessed in relation to psychopathy in several existing cohorts. They could also be incorporated into imaging genetic investigations of psychopathy. The latter avenue is particularly interesting, because we have recently used twin design to document that aberrant structural development in certain brain areas in $\mathrm{AB} / \mathrm{CU}+$ reflects genetic, rather than environmental, vulnerability (Rijsdijk et al., 2010).

\section{Summary of Genetic Research}

Numerous twin studies from different laboratories suggest that both individual and group differences in CU traits are moderately to strongly heritable. Child-specific (nonshared) environmental factors are also important in accounting for individual and group differences in CU traits. However, environmental factors that make children growing up in the same family similar to each other (termed shared environmental factors in twin models) do not typically play a role in individual and group differences in CU traits. Girls with stable high CU traits represent a possible exception, because shared environmental factors appear to be important for the development of CU traits in this group. 
Twin studies can go beyond answering questions about the relative importance of heritable and environmental influences. To date such studies have advanced our knowledge about CU traits in several important ways. First, they have demonstrated that the stability of CU traits is typically driven by genetic influences (particularly in boys), but there are substantial child-specific environmental influences that may contribute to an increasing or decreasing trajectory of CU trait development. Second, monozygotic twin differences data suggest that negative parental practices do not act as a childspecific environmental risk factor for $\mathrm{CU}$, but they may instead reflect genetic vulnerability within families. However, aspects of positive parenting are yet to be investigated within this framework and could be a promising environmental modulator of CU traits. Third, a number of studies have shown that $\mathrm{CU}$ and $\mathrm{AB}$ share a degree of genetic risk and (to a modest extent) child-specific environmental risk factors. Fourth and finally, $\mathrm{AB}$ in the presence (but not absence) of $\mathrm{CU}$ traits appears strongly heritable, suggesting that $\mathrm{CU}$ traits are a useful subtyping index for children with disruptive behaviors.

Research into specific polymorphisms that increase risk of $\mathrm{CU}$ traits or $\mathrm{AB} / \mathrm{CU}+$ is still in its infancy. Furthermore, as far as we are aware, there have been no independent replications of any of the reported findings. Research in this area is likely to advance greatly in the coming decade, including novel epigenetic approaches that may help us uncover mechanisms of gene-environment interaction, studies of rare copy number variants that may affect smaller subsets of individuals at risk for developing psychopathy, or investigations of possible sex-specific genetic risk factors. It is useful to consider the following pointers with regard to current but in particular future molecular genetic investigations. First, there are no genes for psychopathy. Genes code for proteins that influence characteristics such as neurocognitive vulnerabilities that may in turn increase risk for developing psychopathy. Second, genetic risk for psychopathy may only manifest itself under unfavorable environmental circumstances (e.g., Sadeh et al., 2010) and genetic variants implicated in $\mathrm{CU}$ and $\mathrm{AB} / \mathrm{CU}+$ are likely to include several common polymorphisms that confer advantages, as well as disadvantages, depending on the environmental context. Third, we know that the neurocognitive vulnerabilities associated with psychopathy (or risk for development of psychopathy) are at least partially distinct from those associated with $A B$ in general. This suggests that the risk alleles for psychopathy may not be the same risk alleles as those for $A B$ in the absence of CU traits. (For a review of this in relation to 5 HTTLPR, see Glenn, 2011; for a more general proposal of differential genetic vulnerability in $\mathrm{AB} / \mathrm{CU}+$ and $\mathrm{AB} / \mathrm{CU}-$, see Viding \& Jones, 2008.) The study by Sadeh and colleagues (2010) is in line with this possibility, because it demonstrated not only that the long allele of the 5-HTTLPR predisposed individuals to $\mathrm{CU}$ traits in low socioeconomic status environments but also that the short allele of the same gene predisposed individuals to impulsive AB. Buckholtz and Meyer-Lindenberg (2008) have also speculated that the MAOA-L allele, which has received a lot of attention as a risk allele for $\mathrm{AB}$, may predispose to threat reactive and impulsive, rather than psychopathic $\mathrm{AB}$. The MAOA-L genotype is associated with a pattern of hyperreactivity of emotion processing areas of the brain (Meyer-Lindenberg et al., 2006), which is in direct contrast to the pattern typically reported for individuals with psychopathy (e.g., Birbaumer et al., 2005; Kiehl et al., 2001). It is interesting to note that some studies have reported increased vulnerability to $\mathrm{AB}$ in the presence of the high activity MAOA allele (e.g., Manuck, Flory, Ferrell, Man, \& Muldoon, 2000). These may reflect false positive findings, but they could also reflect the relative composition of $\mathrm{CU}+$ and $\mathrm{CU}-$ individuals in different studies.

\section{Functional and Structural MRI Studies}

As outlined in the introductory section, children with $\mathrm{AB} /$ $\mathrm{CU}+$ share an affective profile with adult psychopaths, showing reduced sensitivity to visual or vocal displays of distress emotions and poor modulation of behavior in response to punishment (Blair \& Viding, 2008). In line with the behavioral and experimental neuropsychology data, functional MRI findings for children with $\mathrm{AB} / \mathrm{CU}+$ indicate functional deficits consistent with low emotional responsiveness to others' distress and poor ability to learn from reinforcement information. Aberrant neural functioning (compared to typically developing children or children with ADHD) has been observed for children with $\mathrm{AB} / \mathrm{CU}+$ in the amygdala, ventromedial prefrontal cortex (vmPFC), orbitofrontal cortex (OFC), and caudate, which are brain areas involved in processing basic emotional salience, reinforcement learning, and emotion regulation (see Table 1 for details of these studies).

Two recent studies have reported reduced amygdala activity to others' distress (fearful facial expressions) in children with $\mathrm{AB} / \mathrm{CU}+$ compared to typically developing children or children with ADHD (Jones et al., 2009; Marsh et al., 2008). Marsh et al. also reported reduced functional coupling between the amygdala and $\mathrm{OFC}$ in children with $\mathrm{AB} / \mathrm{CU}+$ when they viewed fearful facial expressions. A recent study from our group explored the differential contributions of $\mathrm{CU}$ traits and conduct problems to amygdala activity in children with conduct problems (Sebastian et al., in press). The unique variance associated with $\mathrm{CU}$ traits was related to decreased amygdala activity, whereas the unique variance associated with conduct problems was associated with increased amygdala activity to affective theory of mind scenarios. One study to date has reported abnormal vmPFC response to punishment in adolescents with $\mathrm{AB} / \mathrm{CU}+$ (Finger, Marsh, \& Mitchell, 2008). In this study, the participants had to choose the "correct" stimulus from a pair of items. From time to time the reinforcement associations reversed and a previously rewarded stimuli became unrewarded, whereas the previously unrewarded stimuli became rewarded. Finger et al. (2008) reported that typically developing children and 
children with ADHD showed a reduction in vmPFC activity following an unexpected punishment. Such reduction in vmPFC activity has been shown to co-occur with prediction error (Mitchell, 2011). In contrast, youth with $\mathrm{AB} / \mathrm{CU}+\mathrm{did}$ not show this reduction in $\mathrm{vmPFC}$ activity. Using a passive avoidance paradigm, where participants had to learn which stimuli were "good" (rewarded) and which were "bad" (unrewarded), Finger et al. (2011) also demonstrated that children with $\mathrm{AB} / \mathrm{CU}+$ showed less OFC and caudate responsiveness to early stimulus-reinforcement exposure and less OFC responsiveness to rewards. These neural differences are likely to index compromised sensitivity to early reinforcement information in the OFC and caudate and generally compromised sensitivity to reward outcome information in the $\mathrm{OFC}$ in adolescents with $\mathrm{AB} / \mathrm{CU}+$. The functional MRI findings in $\mathrm{AB} / \mathrm{CU}+$ are in line with those typically reported in studies of adult psychopaths (e.g., Birbaumer et al., 2005; Kiehl et al., 2001) and suggest functional neural bases for why individuals with $\mathrm{AB} / \mathrm{CU}+$ appear abnormally unaffected by other people's distress and often make and repeat disadvantageous decisions.

To date there have been only two studies that report on structural MRI correlates of $\mathrm{AB} / \mathrm{CU}+$ in children. De Brito et al. (2009) found that compared to typically developing boys, boys with $\mathrm{AB} / \mathrm{CU}+$ had increased grey matter concentration (GMC) in several brain areas implicated in decision making, moral processing, and self-reflection. These included the $\mathrm{OFC}$, insula, anterior cingulate cortex (ACC), posterior cingulate cortex (PCC), and superior temporal cortex. Subsequently, De Brito et al. (2011) showed that compared to typically developing boys, those with $\mathrm{AB} / \mathrm{CU}+$ exhibited decreased white matter concentration in a subset of the brain areas where increased GMC was previously found in this group, including the ACC and superior temporal cortex. These findings indicate that children with $\mathrm{AB} / \mathrm{CU}+$ are characterized by atypical neural structures in many of the same areas where gray and white matter abnormalities have also been reported in adults with psychopathy (Gao, Glenn, Schug, Yang, \& Raine, 2009; Yang \& Raine, 2009). However, it is somewhat puzzling that the direction of the effect (at least for gray matter) is different in the child compared with adult studies. Note that De Brito et al. $(2009,2011)$ studied children who were between 10 and 13 years of age. Recent brain imaging evidence in normative samples suggests that gray matter decreases and white matter increases in several of the brain areas implicated in $\mathrm{AB} /$ $\mathrm{CU}+$ during this period of early adolescence (Gogtay et al., 2004). This is contrary to the pattern observed for the 10- to 13-year-old boys with $\mathrm{AB} / \mathrm{CU}+$, possibly indicative of aberrant brain maturation for this group in early adolescence. These data are not necessarily at odds with the findings from adult studies, which clearly represent a very different developmental stage. Distinct developmental disorders can follow markedly different patterns of structural brain development (Shaw, Gotay, \& Rapoport, 2010) and future longitudinal studies should probe the exact developmental pattern characteristic of $\mathrm{AB} / \mathrm{CU}+$.
A number of functional and structural MRI studies have focused on children with $\mathrm{AB}$ without subtyping on $\mathrm{CU}$ traits (e.g., see reviews of Rubia, 2011; and Sterzer \& Stadler, 2010; see also Fairchild et al., 2011; Passamonti et al., 2010; Rubia et al., 2009), but these are difficult to interpret in the context of $\mathrm{AB} / \mathrm{CU}+$ because the relative composition of those individuals who are high versus low on $\mathrm{CU}$ traits is unclear. Passamonti et al. performed dimensional analyses of CU traits on their sample of adolescents with conduct disorder, who viewed emotional facial expressions in the scanner. They did not find that $\mathrm{CU}$ predicted variance in brain activity, over and above conduct problems. However, the stimuli used in this task were sad rather than fearful faces and the authors did not assess possible suppressor effects between conduct problems and $\mathrm{CU}$, which are known to occur at both the behavioral (e.g., Frick, Lilienfeld, Ellis, Loney, \& Silverthorn, 1999; Hicks \& Patrick, 2006) and neural levels (Sebastian et al., in press). In line with data from adults with psychopathic traits (Buckholtz et al., 2010), Fairchild and colleagues found that $\mathrm{CU}$ traits predicted increased caudate nucleus and ventral striatal grey matter volumes in children with conduct disorder.

\section{Summary of MRI Research}

The sparse MRI evidence base suggests that $\mathrm{AB} / \mathrm{CU}+$ is associated with atypical patterns of brain structure and function, particularly in the areas critical for affective processing, affective decision making, and moral emotions. The findings are broadly in line with those reported in studies of adult psychopaths and suggest neural bases for the types of traits and behaviors associated with $\mathrm{AB} / \mathrm{CU}+$. Specifically, children with $\mathrm{AB} / \mathrm{CU}+$ show lower amygdala reactivity to fearful faces than typically developing children or children with ADHD. They also show abnormal activity in the vmPFC, OFC, and caudate; these are areas associated with prediction error and monitoring of reward outcomes during affective decision making and reversal learning.

Unfortunately none of the studies to date have involved an explicit comparison of children with $\mathrm{AB} / \mathrm{CU}+$ and $\mathrm{AB} / \mathrm{CU}-$, and such studies are clearly needed in the future. A recent study by our group explored the specific contributions of $\mathrm{CU}$ traits and conduct problems on amygdala activity to complex emotional scenes in children with $\mathrm{AB}$ (Sebastian et al., in press). We found that whereas $\mathrm{CU}$ traits (free from variance shared with conduct problems) predicted lower amygdala activity, conduct problems (free from variance shared with $\mathrm{CU}$ traits) predicted the opposite pattern, that is, increased amygdala activity. These data are in line with effects reported in behavioral studies of emotional reactivity in adults (Hicks \& Patrick, 2006) and children (Frick et al., 1999) with AB and suggest that the heterogeneity in previous reports of amygdala response in children with $\mathrm{AB}$ may be partly accounted for by a child's level of CU traits. In addition, extant studies have only utilized a limited number of paradigms. To date these have included a simple gender decision task 
when viewing facial stimuli of emotional and neutral content, passive avoidance learning, reversal learning, and affective and nonaffective theory of mind cartoons. In the future it would be of interest to investigate neural responses in children with $\mathrm{AB} / \mathrm{CU}+$ to stimuli related to empathy, morality, and emotion regulation. Possible sex differences in structural and functional brain correlates of $\mathrm{AB} / \mathrm{CU}+$ are also yet to be explored. Finally, it would be interesting to assess functional and structural brain development longitudinally, including the identification of possible "brain biomarkers" that might predict future behavioral outcomes for children with $\mathrm{AB} /$ $\mathrm{CU}+$. Combining imaging methodologies with genotyping and study of environmental risk is similarly likely to prove informative, particularly as we try to understand the multifinality of outcomes for children with $\mathrm{AB} / \mathrm{CU}+$. Although this group of children are at an increased risk of developing psychopathy, not all of them do so. By combining different levels of analyses longitudinally we will be able to develop an integrated model of $\mathrm{AB}$ and its relation to $\mathrm{CU}$ traits that can better inform approaches to prevention and intervention.

\section{Integrating Genetic and Neuroimaging Findings}

Genetic vulnerability to $\mathrm{CU}+$ may contribute to some of the neural vulnerabilities characteristic of $\mathrm{AB} / \mathrm{CU}+$, and integration of genetic and neuroimaging approaches may yield novel information important for understanding the development of psychopathy. We recently conducted a twin study that investigated whether GMC on those areas that differentiated children with $\mathrm{AB} / \mathrm{CU}+$ from typically developing children were heritable (Rijsdijk et al., 2010). We also investigated whether common genetic influences were important for GMC and $\mathrm{AB} / \mathrm{CU}+$ status and whether such common genetic influences were responsible for the phenotypic association between higher $\mathrm{GMC}$ and $\mathrm{AB} / \mathrm{CU}+$. Of the brain areas that showed group differences and heritable influences, the PCC and ACC shared a moderate degree of genetic influences with $\mathrm{AB} / \mathrm{CU}+$. These common genetic influences were entirely responsible for the phenotypic association between $\mathrm{GMC}$ and $\mathrm{AB} / \mathrm{CU}+$. These findings provide preliminary evidence that the PCC and ACC may constitute intermediate phenotypes for the development of psychopathy. Both PCC and ACC are involved in empathy for pain, moral judgments, and self-referential thinking (including judgments and obligations) and as such represent logical intermediate phenotype markers for the development of psychopathy. It is premature to speculate regarding the putative mechanism by which genes could increase GMC and in turn lead to increased levels of $\mathrm{AB} / \mathrm{CU}+$. However, future imaging genetic studies could investigate the role of specific neurodevelopmental genes in explaining GMC differences between $\mathrm{AB} / \mathrm{CU}+$ and typically developing children. It is also of interest to investigate the genetic contributions to functional brain differences using both twin and candidate gene imaging approaches. For example, it would be important to explore the role of 5-HTTLPR in modulating neural activity to emotional stimuli in children with high levels of CU traits and different levels of social adversity.

\section{Treatment Implications}

Children with $\mathrm{AB} / \mathrm{CU}+$ would be conceptually hypothesized to respond to treatment in a different way than children with $\mathrm{AB} / \mathrm{CU}$ - given their distinct pattern of etiological and neurocognitive vulnerability. For example, we have considered evidence that children with $\mathrm{AB} / \mathrm{CU}+$ have genetic vulnerability to $\mathrm{AB}$ and show functional and structural neural abnormalities that may predispose them to deviant development of emotion processing, reinforcement learning, and empathy. However, few treatment studies have been conducted that have either (a) examined how treatment outcome might vary in relation to a child's level of CU traits or (b) examined whether different forms of intervention may be more or less effective in promoting change in children with high CU traits.

Parenting studies conducted with young children are an exception in the literature. They have provided preliminary evidence for two conclusions regarding the nature of $\mathrm{CU}$ traits in preadolescent children. First, children with high levels of CU traits appear to respond less well to some aspects of typical parenting interventions. Following a 10week standardized parenting program for 3- to 8-year-old children with conduct problems, it was found that high $\mathrm{CU}$ traits uniquely predicted poor response to treatment, even after controlling for family characteristics (Hawes \& Dadds, 2005). Observational data relating to the parent-child interactions in the home indicated that high-CU children differed only in their response to the "time-out" procedure. This suggests differential responsiveness to a traditional treatment component, consistent with the evidence from the experimental literature that these children may be relatively punishment insensitive (Frick \& Viding, 2009). Second, high levels of $C U$ traits appear malleable in a subset of children. In a subsequent study Hawes and Dadds (2007) examined the malleability and stability of CU traits in this sample including at 6-month follow-up. They found that CU scores in a subset of the sample dropped significantly following treatment. Although this change may reflect problems in measuring $\mathrm{CU}$ traits accurately (e.g., parents overreporting these traits at presentation), it seems likely that the effect is consistent with genuine malleability of CU traits in some children. This finding is in line with that reported for older preadolescent children (Pardini, Lochman \& Powell, 2007). A sample of 120 aggressive children in the fifth grade was followed over a 1year period; those exposed to lower levels of physical punishment and reporting greater levels of parental warmth and involvement showed decreases in CU traits over time.

These findings are at least suggestive that parenting practices, which in theory are amenable to change through intervention, may influence levels of CU traits over time. However, the nature of any relationship between parenting and CU traits is likely to be complex. A recent study by Hawes, Dadds, Frost, and Hasking (2011) examined the relationship 
between CU traits and parenting in a large community sample of children aged between 3 and 10 years of age. CU traits predicted change in relation to inconsistent discipline, corporal punishment, and parental involvement with the latter two factors moderated by child age and sex. It is possible therefore that CU traits may serve to elicit escalating levels of harsh and inconsistent discipline by parents. The authors also investigated what predicted change in $\mathrm{CU}$ traits over time. They found that positive parenting (mainly in girls) and parental involvement (mainly in boys) were associated with CU change over time, consistent in part with the findings of Pardini, Lochman, and Powell (2007). These findings suggest a complex set of bidirectional parent-child dynamics that need to be better understood if effective family based interventions are to be tailored to children with conduct problems and high levels of CU traits.

A separate line of research that may have treatment implications has investigated the atypical pattern of eye gaze and eye contact in children with high CU traits. As outlined earlier in this paper, children with high levels of CU traits have deficits in fear recognition and do not automatically orient to the eye region of the face (Dadds \& Rhodes, 2008; Frick \& Viding, 2009; Sylvers et al., 2011). However, when these children were asked to "look at the eyes" of the stimulus faces the recognition deficits disappeared (Dadds et al., 2006; Dadds \& Rhodes, 2008). It has also been shown that 5- to 15-year-old children with high CU traits show consistent impairments in their eye contact with their parents (Dadds et al., 2011). This finding has been replicated in a younger sample in a task requiring a "loving" interaction between the child and their mother (Dadds et al., 2011). Understanding deficits in these domains is potentially critical to intervention in two ways. First, deficits in basic social interaction processes may be relevant in informing targets for parenting and child based interventions. Second, given that most psychologically based intervention relies on establishing an effective therapeutic alliance, it will be important to reconsider traditional approaches to establishing rapport when engaging therapeutically with children with high CU traits.

Behavioral interventions are also being increasingly delivered in school settings (Viding, McCrory, Blakemore, \& Frederickson, 2011). Given that children with $\mathrm{AB} / \mathrm{CU}+$ often come from families characterized by multiple difficulties (where parents are also likely to have genetic and neurocognitive vulnerabilities), school settings may provide an important context for delivering consistent intervention. One of the most commonly studied problem behaviors in the school setting is bullying, and $\mathrm{CU}$ traits and a combination of $\mathrm{CU}$ traits and $\mathrm{AB}$ are associated with increased rates of bullying behavior (e.g., Crapanzano, Frick, Childs, \& Terranova, 2011; Muñoz, Qualter, \& Padgett, 2011; Viding et al., 2009). Neuroscience findings (e.g., Finger et al., 2011; Marsh et al., 2008; Sebastian et al., in press) indicate there is a growing case for developing tailored approaches to reduce bullying behavior in children with $\mathrm{AB} / \mathrm{CU}+$ because they are unlikely to be well served by the most commonly implemented ap- proaches (Smith, Pepler, \& Rigby, 2004). For example, educative approaches often aim to elicit empathy in the bully and focus on the distress they cause other children as a means to engender in them a motivation to change. The second commonly used intervention approach, exemplified by zero-tolerance policies, is essentially punitive and involves exclusion from school and other high-level disciplinary sanctions. The research we have reviewed above indicates that neither of the above approaches is likely to work as effectively in children with CU conduct problems because they have difficulties empathizing and are less responsive to punishment. A more successful approach could involve, for example, the establishment of a system of rewards for behavior incompatible with bullying; in parallel there would be a need to ensure that rewards for bullying behavior (e.g., gaining peer dominance, status, and goods) were minimized, for example, through close supervision by adults or peer mentors. Currently, however, schools rarely implement systemic and peer-supported approaches to bullying (Sherer \& Nickerson, 2010).

Genetic and neuroscience research is helping to inform a model of developmental vulnerability to adult psychopathy. Although this research suggests that children with high $\mathrm{CU}$ traits or $\mathrm{AB} / \mathrm{CU}+$ are genetically and neurocognitively vulnerable, existing research also strongly endorses that $\mathrm{CU}$ traits are malleable during childhood. Longitudinal, genetically informative data suggest that environmental influences account for a substantial proportion of variance in $\mathrm{CU}$ traits and are important for change in these traits. Phenotypic data demonstrated that positive parenting and parental involvement can reduce CU traits over time (Hawes et al., 2011). These data are in line with the notion that, despite genetic risk for $\mathrm{AB} /$ $\mathrm{CU}+$ (or later psychopathy), there are no genes that directly code for psychopathic behavior. As we have outlined, genes code for proteins that influence characteristics such as neurocognitive vulnerabilities that may in turn increase risk for developing psychopathy. This risk may only manifest itself under unfavorable environmental circumstances and genetic variants implicated in $\mathrm{CU}$ and $\mathrm{AB} / \mathrm{CU}+$ are likely to confer advantages, as well as disadvantages, depending on the environmental context.

A particularly important implication from the neuroscience research is that interventions for children with $\mathrm{AB} / \mathrm{CU}+$ may need to be tailored such that they take into account their distinct pattern of neurocognitive vulnerability. Specifically, it may be fruitful to avoid punishment-oriented or explicit empathy induction strategies. Preliminary evidence from behavioral studies suggests that enhancing positive parenting and parental involvement, as well as applying consistent rewards, may represent promising foci for future treatment research.

\section{Development of Psychopathy: Where Do We Go From Here?}

Integrating information across multiple levels of analysis and combining different methodologies within a single study, 
while keeping in mind multiple possible developmental pathways to $\mathrm{AB}$ (equifinality) and different possible outcomes following childhood CU traits (multifinality; Cicchetti \& Rogosch, 1996), is important if the field of developmental psychopathology in general is to advance. In relation to psychopathy this approach is already bearing fruit (Blair \& Viding, 2008; Frick \& Viding, 2009). The current evidence base suggests that $\mathrm{AB}$ is associated with a number of different developmental trajectories, consistent with the notion of equifinality. Different etiological pathways can lead to high levels of $\mathrm{AB}$; as we have seen, children with $\mathrm{AB} / \mathrm{CU}+$ appear to be the most genetically vulnerable to persistent antisocial behavioral problems and in some cases psychopathy. However, the current data also clearly indicate that there are no genes for AB or psychopathy, not even in this group with a stronger genetic predisposition. Rather, variation in genes is likely to code for variation in information/affective processing styles. The information processing style of children with $\mathrm{AB} / \mathrm{CU}+$ is characterized by low emotional reactivity to others' distress and difficulty in learning from sanctions. We have also reviewed neuroimaging evidence that this group of children show related atypical patterns of neural function and structure. Yet these patterns are unlikely to be fixed and determinate. Multifinality characterizes outcomes for children with $\mathrm{AB} / \mathrm{CU}+$ as with all children showing $\mathrm{AB}$. For example, twin studies suggest that environmental factors can influence both the level of CU traits and AB. The data from clinic and community studies are consistent with this notion with preliminary data, indicating that these children with $\mathrm{AB} / \mathrm{CU}+$ may be particularly responsive to warm parenting practices and reward based strategies.

Because neurobiological research on $\mathrm{CU}$ traits and $\mathrm{AB} /$ $\mathrm{CU}+$ is in its infancy, several important questions remain. First, what genes are involved in vulnerability to $\mathrm{AB} / \mathrm{CU}+$ ? In the coming years we are likely to discover that some of the polymorphisms we thought were important may simply represent false positive findings and others, which at first sight appeared less intuitive, may represent true genetic risk. Second, are genetic or neural biomarkers predictive of long-term outcome and treatment response? Because our diagnostics systems are based on behavioral criteria, we can comfortably predict that there will not be a single basis to any given disorder (genetic or otherwise); but we may be able to isolate specific biomarkers that can provide clues to developmental risk. Third, how do both genetic and environmental risk factors pertinent for psychopathy manifest at the neural level across development? Most current research has been cross-sectional in nature. We need a much better picture of how atypical patterns of neural function develop over time in children with $\mathrm{AB} / \mathrm{CU}+$ if we are to tease apart which effects reflect developmental immaturity or delay and which reflect an abnormal pattern of development.

Fourth and finally, although children with $\mathrm{CU}+$ can be found both in early- and adolescent-onset conduct disorder groups, do these groups share common etiological factors for their CU traits? It is possible, for example, that the biological vulnerability associated with $\mathrm{CU}$ traits is similar across the groups, but the timing and nature of environmental influences may differ. It is also conceivable that at least partly distinct biological vulnerabilities could account for manifestations of CU traits in early- and adolescent-onset conduct disorder groups, consistent with the notion of equifinality.

Addressing these questions effectively represents a challenge to basic science research, but further advances in this field will help us better understand how risk factors in childhood may lead to the development of psychopathy in adulthood. We believe that a better delineation of (even putative) causal mechanisms has the potential to inform more effective approaches to prevention and treatment for at-risk children.

\section{References}

Barker, E. D., Oliver, B. R., Viding, E., Salekin, R. T., \& Maughan, B. (2011). The impact of prenatal maternal risk, fearless temperament and early parenting on adolescent callous-unemotional traits: A 14-year longitudinal investigation. Journal of Child Psychology and Psychiatry, 52, 878-888.

Bezdjian, S., Raine, A., Baker, L. A., \& Lynam, D. R. (2011). Psychopathic personality in children: Genetic and environmental contributions. Psychological Medicine, 41, 589-600.

Birbaumer, N., Veit, R., Lotze, M., Erb, M., Hermann, C., Grodd, W., et al. (2005). Deficient fear conditioning in psychopathy: A functional magnetic resonance imaging study. Archives of General Psychiatry, 62, 799-805.

Blair, R. J. R., \& Viding, E. (2008). Psychopathy. In A. Rutter, M. Bishop, D. Pine, D. Scott, S. Stevenson, J. Taylor, et al. (Eds.), Rutter's child and adolescent psychiatry (5th ed., pp. 852-863). Hoboken, NJ: Wiley.

Blair, R. J. R. (2010). Neuroimaging of psychopathy and antisocial behavior: A targeted review. Current Psychiatry Reports, 12, 76-82.

Blonigen, D. M., Carlson, S. R., Krueger, R. F., \& Patrick, C. J. (2003). A twin study of self-reported personality traits. Personality and Individual Differences, 35, 179-197.

Blonigen, D. M., Hicks, B. M., Krueger, R. F., Patrick, C. J., \& Iacono, W. G. (2005). Psychopathic personality traits: Heritability and genetic overlap

with internalizing and externalizing psychopathology. Psychological Medicine, 35, 637-648.

Blonigen, D. M., Hicks, B. M., Krueger, R. F., Patrick, C. J., \& Iacono, W. G. (2006). Continuity and change in psychopathic traits as measured via normal-range personality: A longitudinal-biometric study. Journal of Abnormal Psychology, 115, 85-95.

Bouchard, T. J., \& Loehlin, J. C. (2001). Genes, personality and evolution. Behavioural Genetics, 31, 243-273.

Buckholtz, J. W., \& Meyer-Lindenberg, A. (2008). MAOA and the neurogenetic architecture of human aggression. Trends in Neurosciences, 31, $120-129$.

Buckholtz, J. W., Treadway, M. T., Cowan, R. L., Woodward, N. D., Benning, S. D., Li, R., et al. (2010). Mesolimbic dopamine reward system hypersensitivity in individuals with psychopathic traits. Nature Neuroscience, 13, 419-421.

Cicchetti, D., \& Rogosch, F. A. (1996). Equifinality and multifinality in developmental psychopathology. Development and Psychopathology, 8, 597-600.

Crapanzano, A. M., Frick, P. J., Childs, K., \& Terranova, A. M. (2011). Gender differences in the assessment, stability, and correlates to bullying roles in middle school children. Differences, 694, 677-694.

Dadds, M. R., Jambrak, J., Pasalich, D., Hawes, D. J., \& Brennan, J. (2011) Impaired attention to the eyes of attachment figures and the develop- 
mental origins of psychopathy. Journal of Child Psychology and Psychiatry, 52, 238-245.

Dadds, M. R., Perry, Y., Hawes, D. J., Merz, S., Riddell, A. C., Haines, D. J., et al. (2006). Attention to the eyes reverses fear-recognition deficits in child psychopathy. British Journal of Psychiatry, 189, 280-281.

Dadds, M. R., \& Rhodes, T. (2008). Aggression in young children with concurrent callous-unemotional traits: Can the neurosciences inform progress and innovation in treatment approaches? Philosophical Transactions of the Royal Society B: Biological Sciences, 363, 2567-2576.

Dandreaux, D., \& Frick, P. (2009). Developmental pathways to conduct problems: A further test of the childhood and adolescent-onset distinction. Journal of Abnormal Child Psychology, 37, 375-385.

De Brito, S. A, Mechelli, A., Wilke, M., Laurens, K. R., Jones, A. P., Barker, G. J., et al. (2009). Size matters: Increased grey matter in boys with conduct problems and callous-unemotional traits. Brain, 132, 843-852.

De Brito, S. A., McCrory, E. J., Mechelli, A., Wilke, M., Jones, A. P., Hodgins, S., et al. (2011). Small, but not perfectly formed: Decreased white matter concentration in boys with psychopathic tendencies. Molecular Psychiatry, 16, 476-477.

De Wied, M., van Boxtel, A., Matthys, W., \& Meeus, W. (2011). Verbal, facial and autonomic responses to empathy-eliciting film clips by disruptive male adolescents with high versus low callous-unemotional traits. Journal of Abnormal Child Psychology, 40, 211-223.

Fairchild, G., Passamonti, L., Hurford, G., Hagan, C. C., von dem Hagen, E. A. H., van Goozen, S. H. M., et al. (2011). Brain structure abnormalities in early-onset and adolescent-onset conduct disorder. American Journal of Psychiatry, 6, 1-10.

Finger, E., Marsh, A., \& Mitchell, D. (2008). Abnormal ventromedial prefrontal cortex function in children with psychopathic traits during reversal learning. Archives of General Psychiatry, 65, 586-594.

Finger, E. C., Marsh, A. A., Blair, K. S., Reid, M. E., Sims, C., Ng, P., et al. (2011). Disrupted reinforcement signaling in the orbitofrontal cortex and caudate in youths with conduct disorder or oppositional defiant disorder and a high level of psychopathic traits. American Journal of Psychiatry, $168,152-162$.

Fontaine, N. M. G., McCrory, E. J. P., Boivin, M., Moffitt, T. E., \& Viding, E. (2011). Predictors and outcomes of joint trajectories of callous-unemotional traits and conduct problems in childhood. Journal of Abnormal Psychology, 120, 730-742.

Fontaine, N. M. G., Rijsdijk, F. V., McCrory, E. J. P., \& Viding, E. (2010). Etiology of different developmental trajectories of callous-unemotional traits. Journal of the American Academy of Child \& Adolescent Psychiatry, 49, 656-664.

Forsman, M., Larsson, H., Andershed, H., \& Lichtenstein, P. (2007). Persistent disruptive childhood behavior and psychopathic personality in adolescence: A twin study. British Journal of Developmental Psychology, $25,383-398$.

Forsman, M., Lichtenstein, P., Andershed, H., \& Larsson, H. (2008). Genetic effects explain the stability of psychopathic personality from mid- to late adolescence. Journal of Abnormal Psychology, 117, 606-617.

Forsman, M., Lichtenstein, P., Andershed, H., \& Larsson, H. (2010). A longitudinal twin study of the direction of effects between psychopathic personality and antisocial behaviour. Journal of Child Psychology and Psychiatry, 51, 39-47.

Fowler, T., Langley, K., Rice, F., van den Bree, M. B. M., Ross, K., Wilkinson, L. S., et al. (2009). Psychopathy trait scores in adolescents with childhood ADHD: The contribution of genotypes affecting MAOA, 5HTT and COMT activity. Psychiatric Genetics, 19, 312-319.

Frick, P. J., Cornell, A. H., Barry, C. T., Bodin, S. D., \& Dane, H. E. (2003). Callous-unemotional traits and conduct problems in the prediction of conduct problem severity, aggression, and self-report of delinquency. Journal of Abnormal Child Psychology, 31, 457-470.

Frick, P. J., Lilienfeld, S. O., Ellis, M., Loney, B., \& Silverthorn, P. (1999). The association between anxiety and psychopathy dimensions in children. Journal of Abnormal Child Psychology, 27, 383-392.

Frick, P. J., \& Moffitt, T. E. (2010). A proposal to the DSM-V Childhood Disorders and the ADHD and Disruptive Behavior Disorders Work Groups to include a specifier to the diagnosis of conduct disorder based on the presence of callous-unemotional traits. Unpublished manuscript.

Frick, P. J., \& Viding, E. (2009). Antisocial behavior from a developmental psychopathology perspective. Development and Psychopathology, 21, 1111-1131.
Gao, Y., Glenn, A. L., Schug, R. A., Yang, Y., \& Raine, A. (2009). The neurobiology of psychopathy: A neurodevelopmental perspective. Canadian Journal of Psychiatry, 54, 813-823.

Glenn, A. L. (2011). The other allele: Exploring the long allele of the serotonin transporter gene as a potential risk factor for psychopathy: A review of the parallels in findings. Neuroscience and Biobehavioral Reviews, 35, 612-620.

Gogtay, N., Giedd, J. N., Lusk, L., Hayashi, K. M., Greenstein, D., Vaituziz, A. C., et al. (2004). Dynamic mapping of human cortical development during childhood through early adulthood. Proceedings of the National Academy of Science, 101, 8174-8179.

Hare, R. D., \& Neumann, C. N. (2006). The PCL-R assessment of psychopathy: Development, structural properties, and new directions. In C. J. Patrick (Ed.), Handbook of psychopathy (pp. 58-88). New York: Guilford Press.

Hawes, D. J., \& Dadds, M. R. (2005). The treatment of conduct problems in children with callous-unemotional traits. Journal of Consulting and Clinical Psychology, 73, 737-741.

Hawes, D. J. \& Dadds, M. R. (2007). Stability and malleability of callousunemotional traits during treatment for childhood conduct problems. Journal of Clinical Child and Adolescent Psychology, 35, 347-355.

Hawes, D. J., Dadds, M. R., Frost, A. D. J., \& Hasking, P. A. (2011). Do childhood callous-unemotional traits drive change in parenting practices? Journal of Clinical Child and Adolescent Psychology, 40, 507518.

Hicks, B., \& Patrick, C. (2006). Psychopathy and negative emotionality: Analyses of suppressor effects reveal distinct relations with emotional distress, fearfulness, and anger-hostility. Journal of Abnormal Psychology, 11, 276-287.

Jones, A. P., Laurens, K. R., Herba, C. M., Barker, G. J., \& Viding, E. (2009). Amygdala hypoactivity to fearful faces in boys with conduct problems and callous-unemotional traits. American Journal of Psychiatry, 166, $95-102$.

Jones, A. P., Happé, F. G., Gilbert, F., Burnett, S., \& Viding, E. (2010). Feeling, caring, knowing: Different types of empathy deficit in boys with psychopathic tendencies and autism spectrum disorder. Journal of Child Psychology and Psychiatry, 51, 1188-1197.

Kiehl, K. A., Smith, A. M., Hare, R. D., Mendrek, A., Forster, B. B., Brink, J., et al. (2001). Limbic abnormalities in affective processing by criminal psychopaths as revealed by functional magnetic resonance imaging. Biological Psychiatry, 50, 677-684.

Kumsta, R., Sonuga-Barke, E., \& Rutter, M. (in press). Adolescent callousunemotional traits and conduct disorder in adoptees exposed to severe early deprivation. British Journal of Psychiatry.

Larsson, H., Tuvblad, C., Rijsdijk, F., Andershed, H., Grann, M., \& Lichtenstein, P. (2007). A common genetic factor explains the association between psychopathic personality and antisocial behaviour. Psychological Medicine, 37, 15-26.

Larsson, H., Andershed, H., \& Lichtenstein, P. (2006). A genetic factor explains most of the variation in the psychopathic personality. Journal of Abnormal Psychology, 115, 221-230.

Larsson, H., Viding, E., \& Plomin, R. (2008). Callous-unemotional traits and antisocial behavior. Criminal Justice and Behavior, 35, 197-211.

Lynam, D. R., Derefinko, K. J., Caspi, A., Loeber, R., \& Stouthamer-Loeber, M. (2007). The content validity of juvenile psychopathy: An empirical examination. Psychological Assessment, 19, 363-367.

Manuck, S. B., Flory, J. D., Ferrell, R. E., Mann, J. J., \& Muldoon, M. F. (2000). A regulatory polymorphism of the monoamine oxidase-A gene may be associated with variability in aggression, impulsivity, and central nervous system serotonergic responsivity. Psychiatry Research, 95, 9-23.

Marsh, A. A., \& Blair, R. J. (2008). Deficits in facial affect recognition among antisocial populations: A meta-analysis. Neuroscience and Biobehavioral Reviews, 32, 454-465.

Marsh, A. A., Finger, E. C., Mitchell, D. G., Reid, M. E., Sims, C., Kosson, D. S., et al. (2008). Reduced amygdala response to fearful expressions in children and adolescents with callous-unemotional traits and disruptive behavior disorders. American Journal of Psychiatry, 165, 712-720.

Marsh, A. A., Kozak, M. N., Wegner, D. M., Reid, M. E., Yu, H. H., \& Blair, R. J. R. (2010). The neural substrates of action identification. Social Cognitive and Affective Neuroscience, 5, 392-403.

Meyer-Lindenberg, A., Buckholtz, J. W., Kolachana, B. R, Hariri, A., Pezawas, L., Blasi, G., et al. (2006). Neural mechanisms of genetic risk for impulsivity and violence in humans. Proceedings of the National Academy of Sciences of the United States of America, 103, 6269-6274. 
Mitchell, D. G. (2011). The nexus between decision making and emotion regulation: A review of convergent neurocognitive substrates. Behavioural Brain Research, 217, 215-231.

Munafo, M. R., Brown, S. M., \& Hariri, A. R. (2008). Serotonin transporter (5-HTTLPR) genotype andamygdala activation: A meta-analysis. Biological Psychiatry, 63, 852-857.

Muñoz, L. C. (2009). Callous-unemotional traits are related to combined deficits in recognizing afraid faces and body poses. Journal of the American Academy of Child \& Adolescent Psychiatry, 48, 554-562.

Muñoz, L. C., Qualter, P., \& Padgett, G. (2011). Empathy and bullying: Exploring the influence of callous-unemotional traits. Child Psychiatry and Human Development, 42, 183-196.

Pardini, D. A., \& Fite, P. J. (2010). Symptoms of conduct disorder, oppositional defiant disorder, attention-deficit/hyperactivity disorder, and callous-unemotional traits as unique predictors of psychosocial maladjustment in boys: Advancing an evidence base for DSM-V. Journal of the American Academy of Child \& Adolescent Psychiatry, 49, 11341144.

Pardini, D. A., Lochman, J. E., \& Powell, N. (2007). The development of callous-unemotional traits and antisocial behavior in children: Are there shared and/or unique predictors? Journal of Clinical Child and Adolescent Psychology, 36, 319-333.

Passamonti, L., Fairchild, G., Goodyer, I. M., Hurford, G., Hagan, C. C., Rowe, J. B., et al. (2010). Neural abnormalities in early-onset and adolescence-onset conduct disorder. Archives of General Psychiatry, 67, 729738 .

Rijsdijk, F. V., Viding, E., DeBrito, S., Forgiarini, M., Mechelli, A., Jones, A. P., et al. (2010). Heritable variations in gray matter concentration as a potential endophenotype for psychopathic traits. Archives of General Psychiatry, 67, 406-413.

Rowe, R., Costello, E. J., Angold, A., Copeland, W. E., \& Maughan, B. (2010). Developmental pathways in oppositional defiant disorder and conduct disorder. Journal of Abnormal Psychology, 119, 726-738.

Rubia, K., Smith, A. B., Halari, R., Matsukura, F., Mohammad, M., Taylor, E., et al. (2009). Disorder-specific dissociation of orbitofrontal dysfunction in boys with pure conduct disorder during reward and ventrolateral prefrontal dysfunction in boys with pure ADHD during sustained attention. American Journal of Psychiatry, 166, 83-94.

Sadeh, N., Javdani, S., Jackson, J. J., Reynolds, E. K., Potenza, M. N., Gelernter, J., et al. (2010). Serotonin transporter gene associations with psychopathic traits in youth vary as a function of socioeconomic resources. Journal of Abnormal Psychology, 119, 604-609.

Scheepers, F. E., Buitelaar, J. K., \& Matthys, W. (2011). Conduct disorder and the specifier callous and unemotional traits in the DSM-V. European Child and Adolescent Psychiatry, 20, 89-93.

Sebastian, C. L., McCrory, E. J. P., Cecil, A. M., Lockwood, P. L., De Brito, S. A., Fontaine, N. M. G., et al. (in press). Neural responses to affective and cognitive theory of mind in children with conduct problems and varying levels of callous-unemotional traits. Archives of General Psychiatry.
Sherer, C., \& Nickerson, A. (2010) Anti-bullying practices in American schools: Perspectives of school psychologists. Psychological Schools, 47, 217-229.

Shaw, P., Gogtay, N., \& Rapoport, J. (2010). Childhood psychiatric disorders as anomalies in neurodevelopmental trajectories. Human Brain Mapping, 31, 917-925.

Silverthorn, P., Frick, P. J., \& Reynolds, R. (2001). Timing of onset and correlates of severe conduct problems in adjudicated girls and boys. Journal of Psychopathology and Behavioral Assessment, 23, 171-181.

Smith, P. K., Pepler, D. J., \& Rigby, K. (2004). Bullying in schools: How successful can interventions be? New York: Cambridge University Press.

Sterzer, P., \& Stadler, C. (2009). Neuroimaging of aggressive and violent behaviour in children and adolescents. Frontiers in Behavioral Neuroscience, 3,35 .

Sylvers, P. D., Brennan, P. A., \& Lilienfeld, S. O. (2011). Psychopathic traits and preattentive threat processing in children. Psychological Science. Advance online publication. doi:10.1177/0956797611420730.

Taylor, J., Loney, B. R., Bobadilla, L., lacono, W. G., \& McGue, M. (2003). Genetic and environmental influences on psychopathy trait dimensions in a community sample of male twins. Journal of Abnormal Child Psychology, 31, 633-645.

Viding, E., Blair, R. J. R., Moffitt, T. E., \& Plomin, R. (2005). Evidence for substantial genetic risk for psychopathy in 7-years-olds. Journal of Child Psychology and Psychiatry, 46, 592-597.

Viding, E., Fontaine, N. M. G., Oliver, B. R., \& Plomin, R. (2009). Negative parental discipline, conduct problems and callous-unemotional traits: Monozygotic twin differences study. British Journal of Psychiatry, 195, 414-419.

Viding, E., Frick, P. J., \& Plomin, R. (2007). Aetiology of the relationship between callous-unemotional traits and conduct problems in childhood. British Journal of Psychiatry, 49, 33-38.

Viding, E., Hanscombe, K. B., Curtis, C. J. C., Davis, O. S. P., Meaburn, E. L., \& Plomin, R. (2010). In search of genes associated with risk for psychopathic tendencies in children: A two-stage genome-wide association study of pooled DNA. Journal of Child Psychology and Psychiatry, 7, 780-788.

Viding, E., \& Jones, A. P. (2008). Cognition to genes via the brain in the study of conduct disorder. Quarterly Journal of Experimental Psychology, 61, 171-181.

Viding, E., Jones, A. P., Frick, P. J., Moffitt, T. E., \& Plomin, R. (2008). Heritability of antisocial behaviour at 9: Do callous-unemotional traits matter? Developmental Science, 11, 17-22.

Viding, E., McCrory, E. J., Blakemore, S.-J., \& Frederickson, N. (2011). Behavioural problems and bullying at school: Can cognitive neuroscience shed new light on an old problem? Trends in Cognitive Sciences, 15, 289-291.

Vizard, E., Hickey, N., \& McCrory, E. (2007). Developmental trajectories associated with juvenile sexually abusive behaviour and emerging severe personality disorder in childhood: 3-Year study. British Journal of Psychiatry, 190, S27-S32.

Yang, Y., \& Raine, A. (2009). Prefrontal structural and functional brain imaging findings in antisocial, violent and psychopathic individuals: A metaanalysis. Psychiatry Research, 174, 81-88. 
